\title{
Metabotropic glutamate receptors regulate differentiation of embryonic stem cells into GABAergic neurons
}

\author{
I Sarichelou ${ }^{1,6}$, I Cappuccio ${ }^{1,2,6}$, F Ferranti ${ }^{1}$, P Mosillo ${ }^{1}$, C Ciceroni ${ }^{1,3}$, P Sale ${ }^{4,5}$, F Stocchi ${ }^{4}$, G Battaglia ${ }^{3}$, F Nicoletti ${ }^{1,3}$ and \\ D Melchiorri ${ }^{x, 1,4}$
}

\begin{abstract}
Mouse embryonic stem (ES) cells were stimulated to differentiate either as adherent monolayer cultures in DMEM/F12 supplemented with N2/B27, or as floating embryoid bodies (EBs) exposed to $1 \mu \mathrm{M}$ retinoic acid (RA) for 4 days, starting from 4 DIV, and subsequently re-plated in DMEM/F12 medium. Adherent monolayer cultures of ES cells expressed mGlu5 receptors throughout the entire differentiation period. Selective pharmacological blockade of mGlu5 receptors with methyl-6(phenylethynyl)-pyridine (MPEP) (1 $\mu \mathrm{M}$, added once a day) accelerated the appearance of the neuronal marker, $\beta$-tubulin. In addition, treatment with MPEP increased the number of cells expressing glutamate decarboxylase-65/67 $\left(\mathrm{GAD}_{65 / 67}\right)$, a marker of GABAergic neurons. In floating EBs, mGlu5 receptors are progressively replaced by mGlu4 receptors. The orthosteric mGlu4/6/ 7/8 receptor agonist, L-2-amino-4-phosphonobutanoate (L-AP4), or the selective mGlu4 receptor enhancer, PHCCC, - both combined with RA at concentrations of $30 \mu \mathrm{M}$ - increased the expression of both $\beta$-tubulin and $\mathrm{GAD}_{65 / 67}$, inducing the appearance of fully differentiated neurons that released GABA in response to membrane depolarization. We conclude that mGlu receptor subtypes regulate neuronal differentiation of ES cells in a context-dependent manner, and that subtype-selective ligands of these receptors might be used for the optimization of in vitro protocols aimed at producing GABAergic neurons from ES cells.
\end{abstract}

Cell Death and Differentiation (2008) 15, 700-707; doi:10.1038/sj.cdd.4402298; published online 4 January 2008

Metabotropic glutamate (mGlu) receptors are generally considered as neurotransmitter receptors activated by the glutamate released from nerve terminals, and involved in the regulation of synaptic plasticity. However, growing evidence extends the function of mGlu receptors to fundamental processes of developmental biology, such as cell proliferation, differentiation and survival. Different mGlu receptor subtypes are expressed and functional at early stages in the embryonic brain that precede synapse formation, ${ }^{1-4}$ and exert differentiative effects on neuronal, ${ }^{5,6} \mathrm{glial}^{7}$ and oligodendrocyte progenitor cells. ${ }^{8} \mathrm{mGlu}$ receptors are found in peripheral cells that do not receive synaptic innervation (such as thymocytes, hepatocytes, keratinocytes, melanocytes, osteoblasts, and cells of the male germ line), and that, with the exception of melanocytes, do not originate from the neural crest. ${ }^{9}$ Individual mGlu receptors have been detected in cancer cells both inside and outside the CNS. ${ }^{10-13}$ In addition, mGlu receptor subtypes with a long $\mathrm{C}$-terminal domain are endowed with 'constitutive activity', and are therefore active in the absence of extracellular glutamate. ${ }^{14}$ These data suggest that mGlu receptors are involved in the regulation of general processes of cell biology that are common to developing cells, cells of peripheral organs, and cancer cells. mGlu receptors form a family of eight subtypes, classified into three groups on the basis of their amino-acid sequence, ligand selectivity, and transduction pathways. Group-I mGlu receptors (mGlu1 and -5 receptors) are coupled to Gq proteins and their activation stimulates inositol phospholipid hydrolysis; group-II (mGlu2 and -3 ) and group-III (mGlu4, -6, -7, and -8) receptors are coupled to $\mathrm{Gi} / \mathrm{Go}$ proteins. Activation of group-II and group-III mGlu receptor subtypes inhibits adenylyl cyclase activity, inhibits voltage-sensitive $\mathrm{Ca}^{2+}$ channels, and activate $\mathrm{K}^{+}$ channels (for a review, see De Blasi et al. ${ }^{15}$ ). We have found that cultured mouse embryonic stem (ES) cells express mGlu5 receptors, the activation of which supports the selfrenewal of ES cells in cooperation with leukemia inhibitory factor (LIF). ${ }^{16,17}$ Pharmacological blockade or knockdown of mGlu5 receptors in ES cells cultured in the presence of LIF drives cell differentiation towards the neuroectoderm lineage. When ES cells are induced to differentiate into cells of the three germ layers by the formation of embryoid bodies (EBs), mGlu5 receptors are replaced by mGlu4 receptors. ${ }^{18}$ Pharmacological activation of mGlu4 receptors in the presence of neuronal inductive cues (e.g. retinoic acid (RA)) amplified

\footnotetext{
${ }^{1}$ Department of Human Physiology and Pharmacology, University of Rome 'Sapienza', Rome, Italy; ${ }^{2}$ IRCCS G Mondino, Pavia, Italy; ${ }^{3}$ INM Neuromed, Pozzilli, Italy; ${ }^{4}$ IRCCS San Raffaele Pisana, Roma, Italy and ${ }^{5}$ Department of Experimental Medicine and Pathology, University of Rome 'Sapienza', Rome, Italy

*Corresponding author: D Melchiorri, Department of Human Physiology and Pharmacology, University of Rome 'Sapienza', Piazzale Aldo Moro 5, Rome 00185, Italy. Tel: + 3906 49912969; Fax: + 3906 4450307; E-mail: daniela.melchiorri@uniroma1.it

${ }^{6}$ First co-authors.

Keywords: mouse embryonic stem cells; metabotropic glutamate receptors; neuronal differentiation

Abbreviations: L-AP4, L-2-amino-4-phosphonobutanoate; EBs, embryoid bodies; ES cells, embryonic stem cells; GAD $65 / 67$, glutamate decarboxylase-65/67; mGlu receptors, metabotropic glutamate receptors; MPEP, methyl-6-(phenylethynyl)-pyridine; PHCCC, $n$-phenyl-7-(hydroxyimino)cyclopropa[b]chromen-1a-carboxamide; $\mathrm{RA}$, retinoic acid; $\mathrm{TH}$, tyrosine hydroxylase

Received 27.7.07; revised 16.11.07; accepted 21.11.07; Edited by M Piacentini; published online 04.1.08
} 
differentiation of EBs towards cells of the neuronal lineage leading to increased expression of the early neural markers DIx-2 and Nestin. ${ }^{18}$ We now show that modulation of mGlu5 and mGlu4 receptors in ES cells exposed to different culture conditions favours cell differentiation towards GABAergic neurons.

\section{Results}

We moved from the findings that (i) undifferentiated ES cells cultured in the presence of LIF express mGlu5 receptors, but not other mGlu receptor subtypes; ${ }^{16}$ (ii) pharmacological blockade of mGlu5 receptors induces differentiation towards the neuroectoderm lineage; ${ }^{16}$ (iii) in ES cells differentiating into EBs, mGlu5 receptors are progressively replaced by mGlu4 receptors ${ }^{18}$ and (iv) activation of mGlu4 receptors enhances the expression of early neural markers in EBs treated with RA. ${ }^{18}$ To further investigate the role of mGlu5 and mGlu4 receptors in ES cell differentiation, we used two different differentiation protocols: (i) cultures of adherent ES cells exposed to serum-free N2B27 medium, which favours neuronal differentiation ${ }^{19}$ and (ii) floating cultures of EBs exposed to all-trans-RA $(1 \mu \mathrm{M})$ according to the $4-/ 4+$ protocol (i.e. 4 days without and 4 days with RA), and then cultured in DMEM/F12/N2 medium for 6 or 12 days.

Pharmacological blockade of mGlu5 receptors enhances neuronal differentiation towards a GABAergic phenotype in cultured adherent ES cells. Monolayer cultures of ES cells cultured in N2B27 medium showed a time-dependent increase in the number of $\beta$-tubulin-expressing cells from $11.34 \pm 1.59 \%$ at 12 DIV to $63.7 \pm 2.6$ at 18 DIV (see below). This allowed us to examine the role of mGlu5 receptors in neuronal differentiation. ES cells expressed mGlu5 receptors constantly throughout the differentiation period (from 1 to 12 DIV) (see Supplementary information, Figure 1). The high levels of glutamate detected in the culture medium (extracellular glutamate concentration ranged from $1.4 \pm 0.1 \mu \mathrm{M}$ on 1 DIV to $6.6 \pm 0.5 \mu \mathrm{M}$ on 12 DIV) masked any potential effect of orthosteric agonists of mGlu5 receptors under our experimental conditions. Hence, we used the non-competitive mGlu5 receptor antagonist, MPEP, to unravel the role of mGlu5 receptors in cell differentiation. By definition, MPEP blocks mGlu5 receptors independently of the concentrations of ambient glutamate. ${ }^{20,21}$ Exposure of cultures to MPEP ( $1 \mu \mathrm{M}$, added everyday starting from $1 \mathrm{DIV})$ increased the expression of $\beta$-tubulin at 12 DIV as shown by western blot analysis (Figure 1a). Immunocytochemical analysis revealed that the increase was due to a greater percentage of $\beta$-tubulinexpressing cells rather than to an increased protein expression per single cell (Figure 2a). No change in $\beta$-tubulin expression was found at $18 \mathrm{DIV}$, suggesting that mGlu5 receptor blockade accelerated differentiation of ES cells into neuron-like cells (Figures $1 \mathrm{~b}$ and $2 \mathrm{~b}$ ). Exposure of ES cells to N2B27 medium is known to favour GABAergic differentiation. ${ }^{19}$ Accordingly, western blot analysis performed in 18 DIV cultures revealed the presence of two bands corresponding to the two isoforms, 65 and 67, of the GABA-synthesizing enzyme, GAD, which is found in GABAergic neurons (Figure 3a). Immunocytochemical analysis showed that about $20-25 \%$ of cells were immunopositive for $\mathrm{GAD}_{65 / 67}$ (Figure $3 \mathrm{~b}$ ). No immunoreactivity for
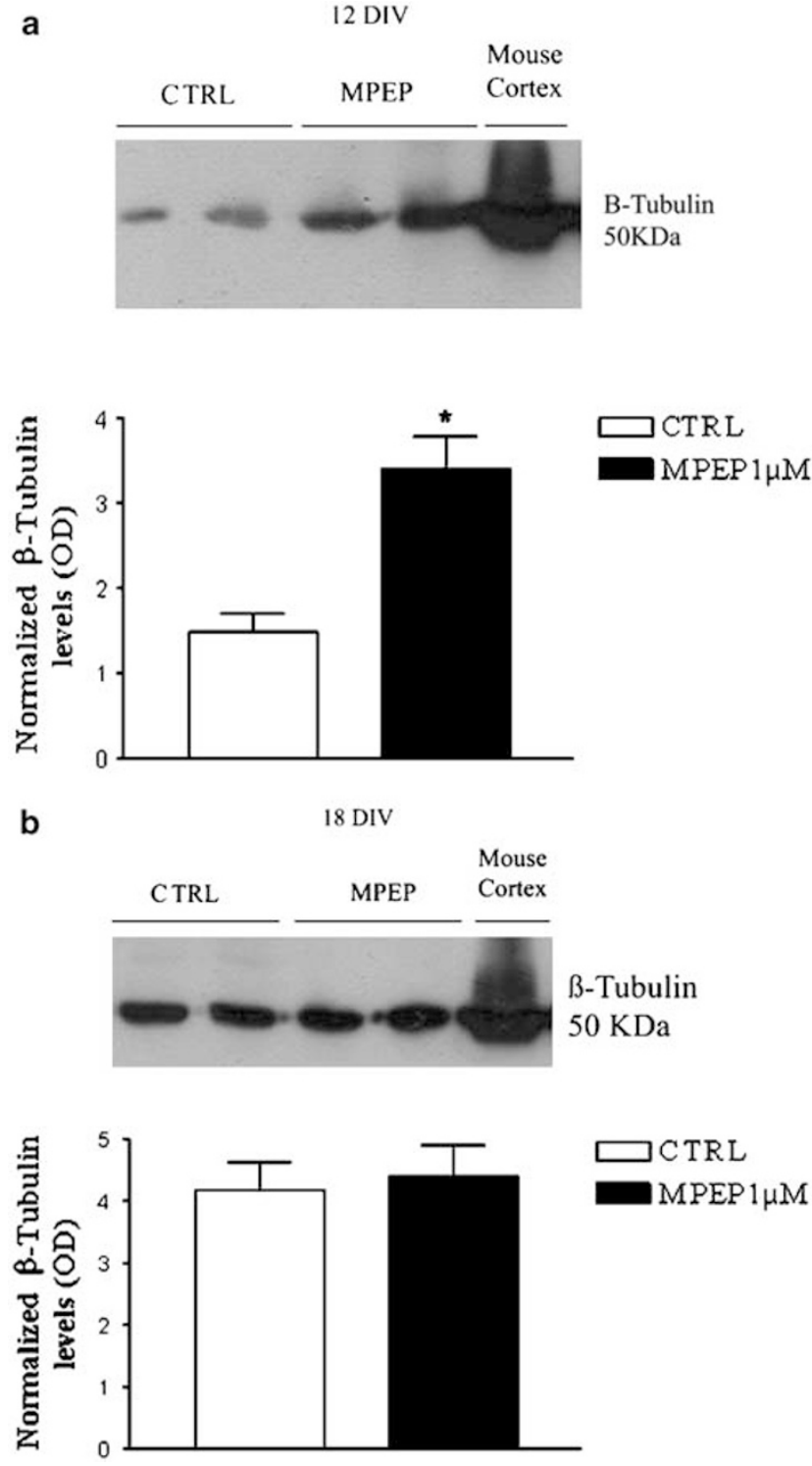

Figure 1 Immunoblot analysis of $\beta$-tubulin in cultured ES cells differentiating in response to the N2B27 medium and treated with or without $1 \mu \mathrm{M}$ MPEP (applied every day since 1 DIV) for 12 or 18 days is shown in (a) and (b), respectively. Values were normalized with respect to the amount of proteins loaded on the gel by staining with Indian ink (see Materials and Methods section) and are means \pm S.E.M. of four determinations. ${ }^{*} P<0.05$ (Student's $t$-test) versus control cells (CTRL)

$\mathrm{GAD}_{65 / 67}$ was observed at 12 DIV (data not shown). Treatment with MPEP greatly increased the expression of $\mathrm{GAD}_{65 / 67}$ at 18 DIV as revealed by western blot analysis (Figure $3 a$ ), but failed to induce the de novo expression of $\mathrm{GAD}_{65 / 67}$ at 12 DIV (not shown). Immunocytochemical analysis performed at 18 DIV showed that a larger number of cells $(52 \pm 2.4 \%$ versus $26+1.6 \%$ ) were labelled by $\mathrm{GAD}_{65 / 67}$ antibody following MPEP treatment compared to control cultures (Figure $3 b$ ). We could not detect any expression of tyrosine hydroxylase in our cultures (see Supplementary information, Figure 2a). In addition, cell differentiation into putative $\mathrm{GFAP}^{+}$astrocytes did not change after exposure to MPEP, as assessed by 
12 DIV

CTRL
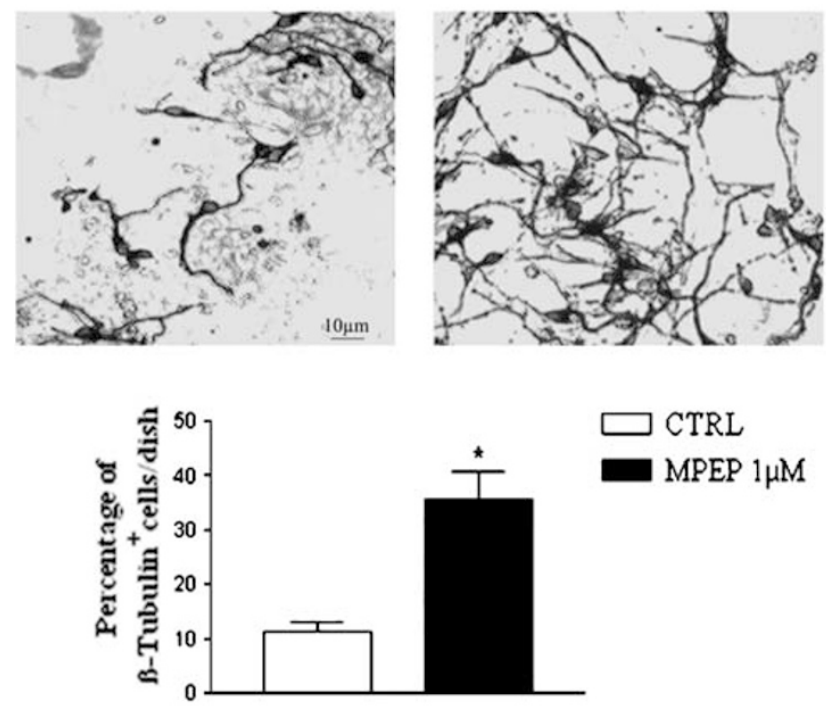

b

18 DIV

CTRL
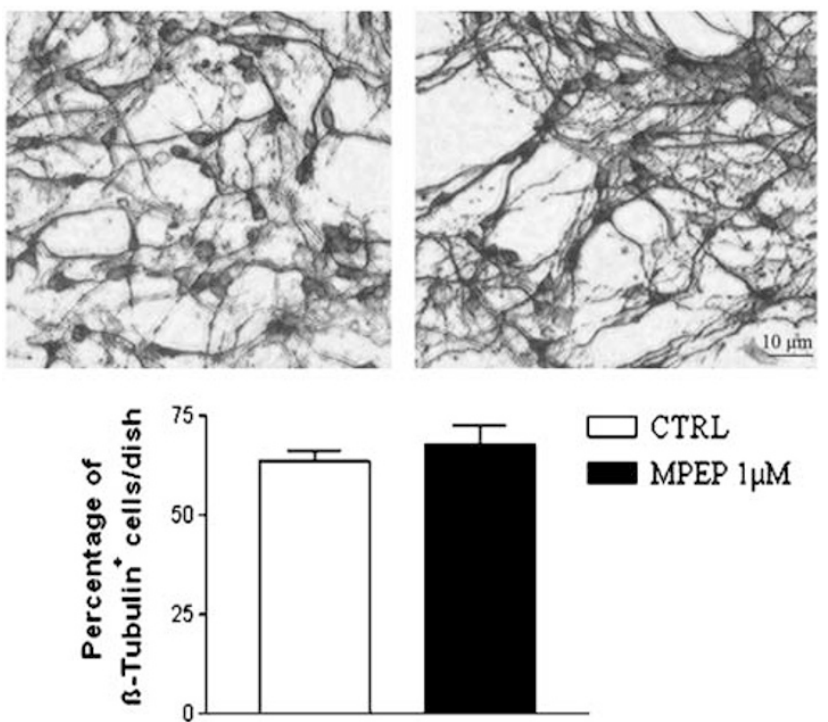

Figure 2 Immunocytochemical analysis of $\beta$-tubulin-expressing cells treated with or without $1 \mu \mathrm{M}$ MPEP (applied every day since $1 \mathrm{DIV}$ ) for 12 or 18 days is shown in (a) and (b), respectively. $\beta$-Tubulin ${ }^{+}$cells are stained in black gray staining is nonspecific and is observed in culture stained without the primary antibody (not shown). Values are means \pm S.E.M. of six individual culture dishes (average from three random microscopic fields per dish) from two independent experiments. ${ }^{*} P<0.05$ (Student's $t$-test) versus control cells (CTRL)

immunoblot analysis and immunocytochemistry (see Supplementary information, Figures $2 a$ and $b$ ).

Pharmacological activation of mGlu4 receptors enhances neuronal differentiation towards a GABAergic phenotype in cultured EBs exposed to RA. ES cells differentiating into EBs express functional mGlu4 receptors. ${ }^{18}$ Exposure to RA a
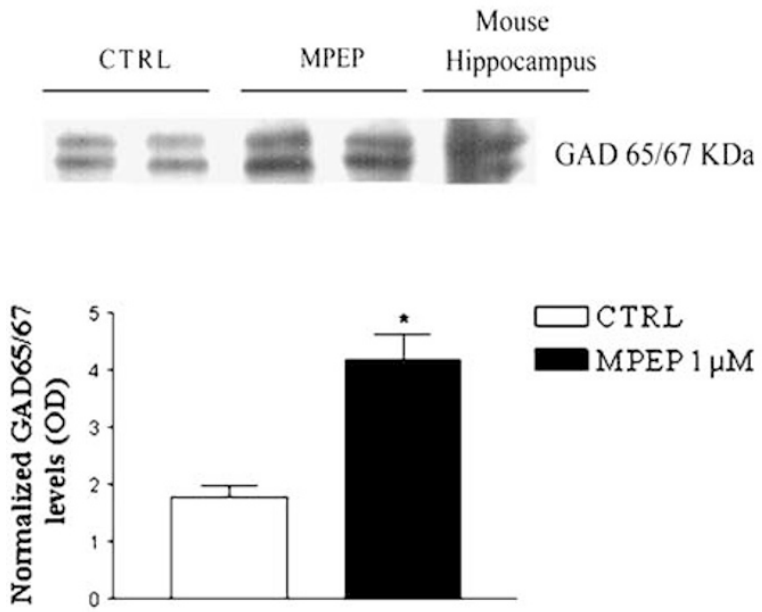

b

CTRL

MPEP $1 \mu \mathrm{M}$
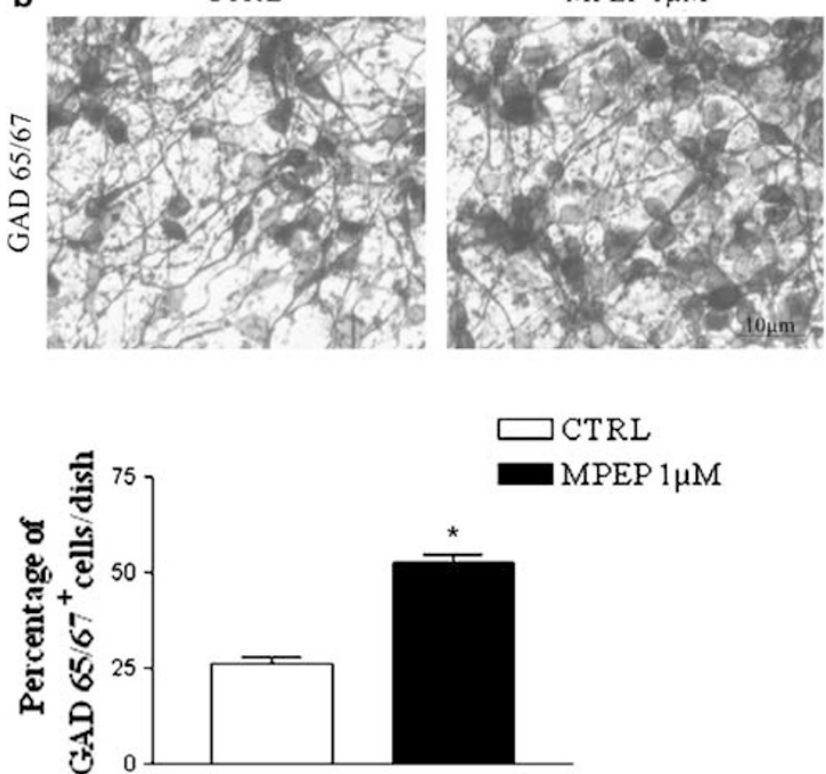

Figure 3 Immunoblot (a) and immunocytochemical (b) analysis of $\mathrm{GAD}_{65 / 67}$ in cells treated with or without $1 \mu \mathrm{M}$ MPEP (applied every day since $1 \mathrm{DIV}$ ) for 18 days. Values were normalized with respect to the amount of proteins loaded on the gel by staining with Indian ink (see Materials and Methods section). In (a), normalized densitometric values are means \pm S.E.M. of $4-5$ determinations. ${ }^{*} P<0.05$ (Student's $t$-test) versus control cells (CTRL). In (b), GAD ${ }^{+}$cells are stained in black gray staining is nonspecific and is observed in culture stained without the primary antibody (not shown). Values are means + S.E.M. of six individual culture dishes (average from three random microscopic fields per dish) from two independent experiments. ${ }^{*} P<0.05$ (Student's $t$-test) versus control cells (CTRL)

according to the protocol $4-/ 4+$ (see the Materials and Methods section) followed by plating on gelatin-coated dishes in DMEM/F12 medium for additional 6 DIV (14 DIV cultures) increased the expression of $\beta$-tubulin with respect to control cultures, as shown by western blot analysis (Figure 4a). Addition of the group III mGlu receptor agonist, L-AP4 $(30 \mu \mathrm{M})$ or the selective mGlu4-positive modulator, PHCCC $(30 \mu \mathrm{M})$, during the 4 days of RA exposure, greatly enhanced the expression of $\beta$-tubulin (Figure 4a). Immunocytochemical 
analysis performed in 14 DIV cultures showed that activation of mGlu4 receptors induced a dramatic change in the morphology of $\beta$-tubulin-expressing cells, leading to the appearance of a more mature cell phenotype characterized by extensive dendritic arborization (Figure 5). Treatment of cultured ES cells with high concentrations of RA $(1-2 \mu \mathrm{M})$ is known to favour differentiation into glutamatergic and GABAergic neurons. ${ }^{22,23}$ Pharmacological activation of mGlu4 receptors with L-AP4 or PHCCC during exposure to RA further amplified the expression of $\mathrm{GAD}_{65 / 67}$, as shown by western blot analysis (Figure 4b) and immunocytochemistry (Figure 5). To further characterize $\mathrm{GAD}_{65 / 67}^{+}$cells, we measured the release of $\left[{ }^{3} \mathrm{H}\right] \mathrm{GABA}$ in control cells and in cells exposed to depolarizing concentrations of $\mathrm{K}^{+}(50 \mathrm{mM}$, added as $\mathrm{KCl})$, in cultures at 14 or 20 DIV. Cultures at 20 DIV exposed to L-AP4 and RA, but not to $R A$ alone, released $\left[{ }^{3} \mathrm{H}\right] \mathrm{GABA}$ in response to $50 \mathrm{mM} \mathrm{K}^{+}$ (Figure 6). No $\left[{ }^{3} \mathrm{H}\right] \mathrm{GABA}$ release was detected in cultures at 14 DIV (data not shown). Knowing that mGlu4 receptors are
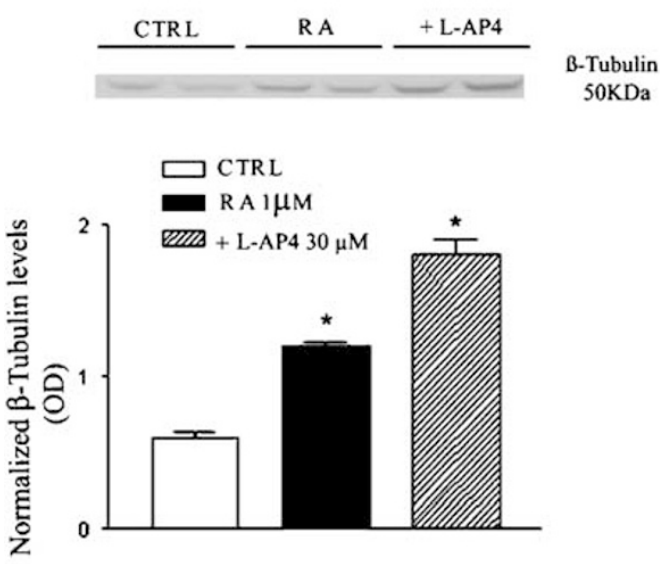

b $\quad$ CTRL $\stackrel{\text { RA }}{=}=$

GAD $65 / 67 \mathrm{KDa}$

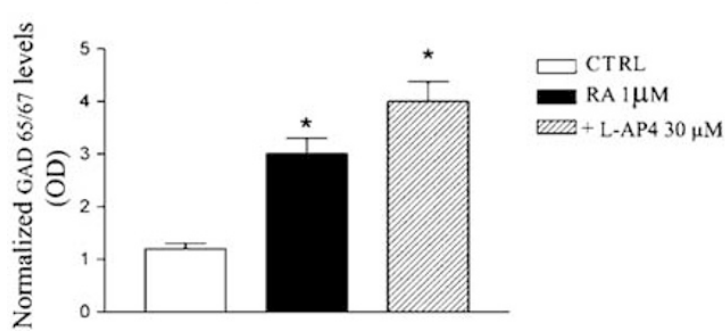

14 DIV
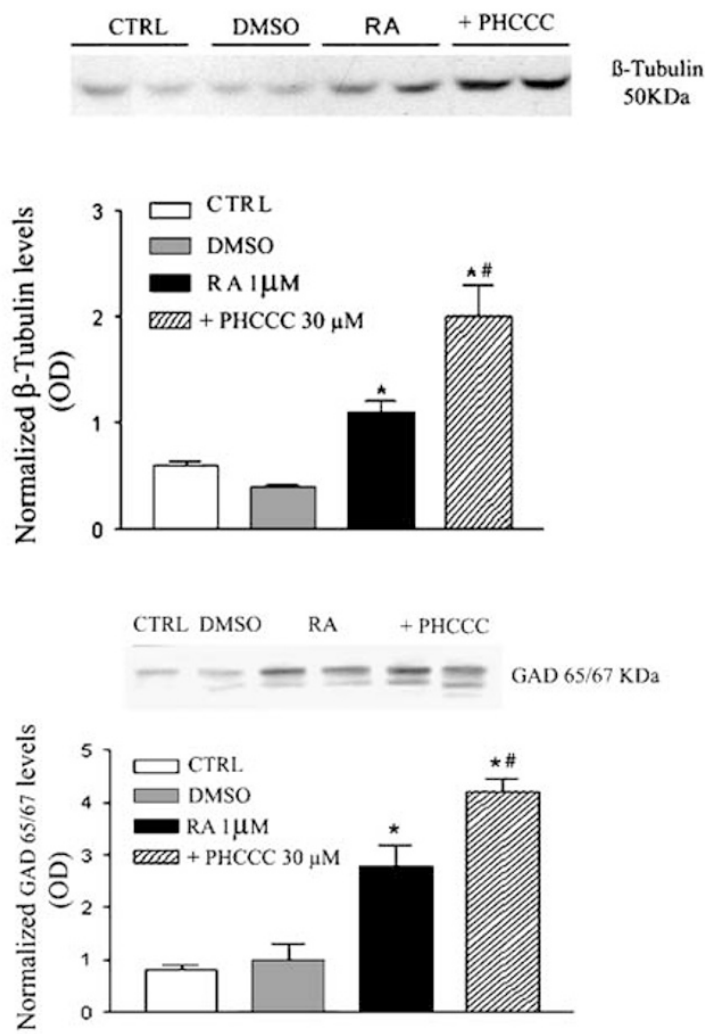

Figure 4 Immunoblot analysis of $\beta$-tubulin (a) and $\mathrm{GAD}_{65 / 67}$ (b) in cells of embryoid bodies (EBs) differentiating in response to retinoic acid (RA) and treated with either L-AP4 or PHCCC. Values were normalized with respect to the amount of proteins loaded on the gel by staining with Indian ink (see Materials and Methods section) and are means \pm S.E.M. of six individual determinations. ${ }^{*} P<0.05$ (one-way ANOVA + Fisher's PLSD) versus untreated control cells (CTRL) or versus cells treated with DMSO alone; ${ }^{\#} P<0.05$ versus cells treated with RA (\#)

14 DIV
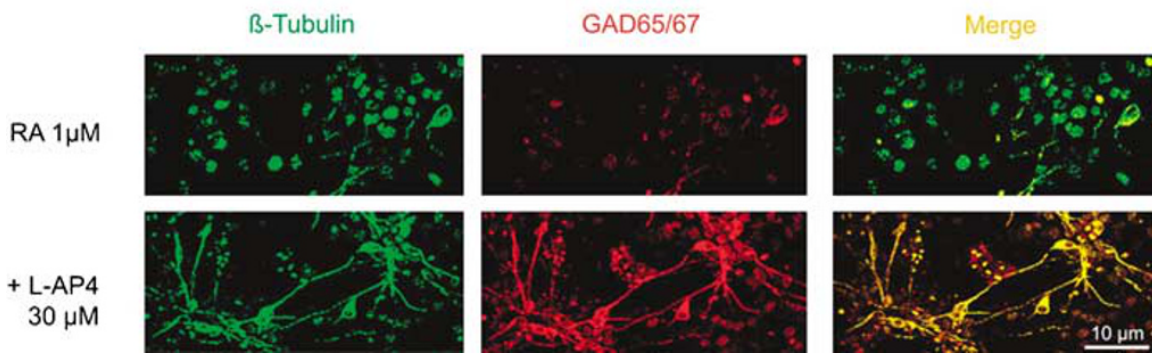

Figure 5 Confocal analysis of $\beta$-tubulin and GAD activity in cells of EBs treated for 4 days with RA in the absence or presence of L-AP4, and examined at 14 DIV. $\beta$-Tubulin fluorescence is in green; $\mathrm{GAD}_{65 / 67}$ fluorescence is in red. Note that in the merged image, the presence of red fluorescence in the absence of green fluorescence is a staining artefact 
negatively coupled to adenylyl cyclase activity, ${ }^{24}$ we examined whether a reduction in cAMP formation could mediate the differentiating effect of mGlu4 receptor agonists. Addition of PHCCC $(30 \mu \mathrm{M})$ to EBs inhibited forskolin-stimulated cAMP formation (Figure 7 ), indicating that mGlu4 receptors retain their canonical transduction pathway in cells of EBs. We therefore attempted to revert the inhibition of CAMP formation by using the cell permeable, non-metabolizable cAMP analogue, 8-Br-cAMP. 8-Br-cAMP (1 mM) was applied daily to cultured EBs during the 4-day exposure to RA and/or PHCCC; cells were then plated in DMEM/F12, and cell differentiation into putative GABAergic neurons was

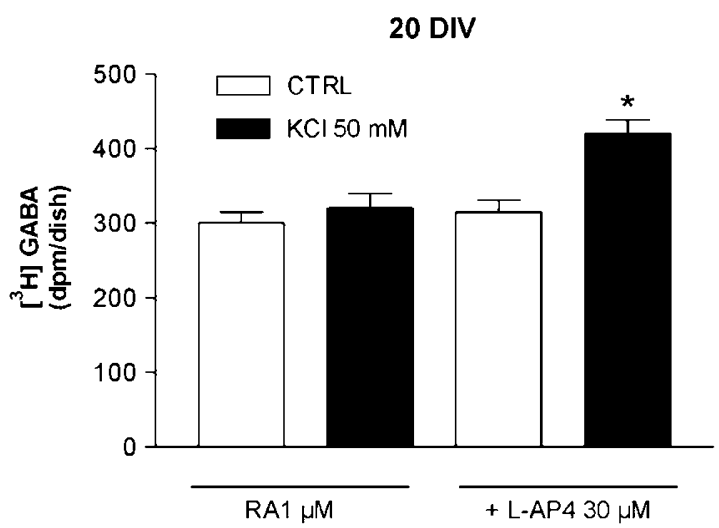

Figure $6\left[{ }^{3} \mathrm{H}\right] \mathrm{GABA}$ release stimulated by $50 \mathrm{mM} \mathrm{K}^{+}$in cells of EBs treated with RA in the absence or presence of L-AP4, and examined at $20 \mathrm{DIV}$. Values are means \pm S.E.M. of six individual determinations. ${ }^{*} P<0.05$ (Student's $t$-test) versus control cells not stimulated with $50 \mathrm{mM} \mathrm{K}{ }^{+}$(CTRL)

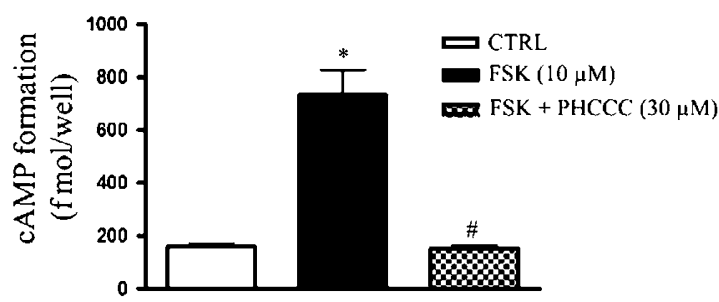

Figure 7 Measurement of CAMP levels in cells of EBs exposed to forskolin (FSK, $10 \mu \mathrm{M})$ combined with or without PHCCC $(30 \mu \mathrm{M})$ for 25 min. Experiments were performed in the presence of $0.5 \mathrm{mM}$ isobutylmethylxanthine. Values are the means \pm S.E.M. of eight individual determinations. $P<0.05$ (one-way ANOVA + Fisher's PLSD) versus controls $\left(^{*}\right)$ or forskolin alone (\#) assessed 6 days later by immunocytochemistry. Interestingly, cultures that had been treated with $\mathrm{RA}+8-\mathrm{Br}-\mathrm{cAMP}$ with or without PHCCC still showed large cell aggregates reminiscent of EBs after 6 days of incubation in DMEM/F12 (Figure 8). Pretreatment with 8-Br-cAMP largely precluded cell differentiation into GABAergic neurons. Only a minority of cells exposed to 8-Br-cAMP and PHCCC (always in combination with $R A$ ) were immunoreactive for $G A D_{65 / 67}$ and detached from the large aggregates. These cells were less differentiated and did not show the dendritic branching typical of cells exposed to RA+PHCCC without 8-Br-cAMP (Figure 8). Similar results were obtained by using L-AP4 instead of PHCCC (not shown).

We could not detect any expression of tyrosine hydroxylase in 14 DIV cultures exposed to RA in the absence or presence of L-AP4 (see immunoblot in Supplementary information, Figure 3a). A minority of cells treated with RA differentiated into putative astrocytes, as detected by GFAP immunostaining. Astrocyte differentiation was not affected by L-AP4 applied in combination with RA for 4 days (see immunoblot and fluorescent immunostaining in Supplementary information, Figures $3 a$ and $b$ ).

\section{Discussion}

Repair of neural network through regeneration of damaged neurons by resident adult stem cells often fails because stem cells residing in the adult brain are generally programmed to give rise to late-born interneurons or glial cells. Thus, exogenous cells are needed to rebuild the neural circuitry, and cell replacement therapy is considered as one of the most promising therapeutic approaches in the field of neurodegenerative diseases. ${ }^{25} \mathrm{ES}$ cells are potential candidates for cell replacement therapy because they are highly plastic and can easily differentiate into any kind of somatic cell. It is intuitive that undifferentiated ES cells have a better chance to survive once they are transplanted into a recipient brain. However, these cells need to be committed towards the neuronal lineage to successfully replace degenerating neurons without giving rise to uncontrolled proliferating cells. This highlights the importance of unravelling the molecular determinants that regulate ES cell differentiation. We have shown here that specific mGlu receptor subtypes critically regulate neuronal differentiation of ES cells, and that ligands of these subtypes may be used in differentiation protocols to improve the yield of
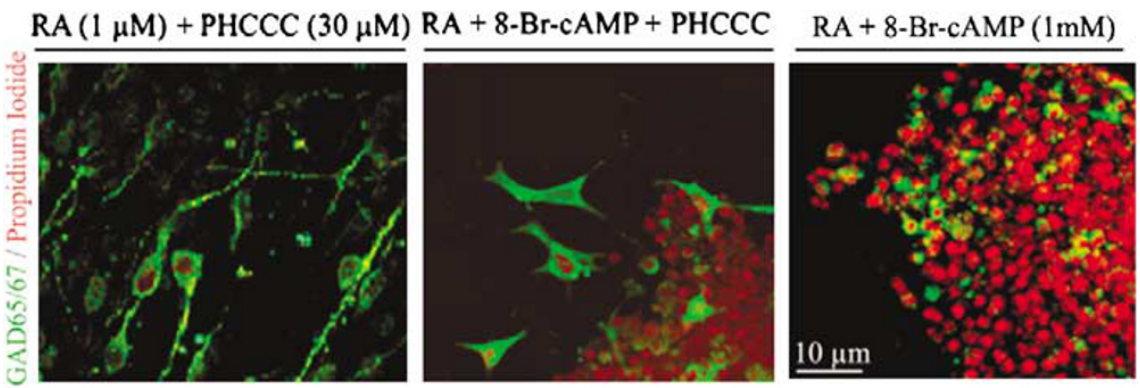

Figure 8 Confocal analysis of $\mathrm{GAD}_{65 / 67}$ in cells of EBs treated for 4 days with $\mathrm{RA}$ in the absence or presence of $\mathrm{PHCCC}(30 \mu \mathrm{M})$ and 8-Br-cAMP (1 mM), and examined 6 days later (i.e. at $14 \mathrm{DIV}$ ). $\mathrm{GAD}_{65 / 67}$ immunofluorescence is in green; nuclear staining is in red (propidium iodide). Note that large cell aggregates are present in cultures exposed to 8-Br-cAMP, and that GAD ${ }^{+}$cells are devoid of dendritic branching in cultures exposed to 8-Br-cAMP 
specific neuronal phenotypes. Interestingly, the identity of the 'targeted' mGlu receptor subtype strictly depends on the differentiation protocol.

Previous studies have shown that the mGlu5 receptor is the only mGlu receptor subtype expressed by undifferentiated ES cells, and that endogenous activation of mGlu5 receptors sustains self-renewal of these cells. ${ }^{16,17}$ Pharmacological blockade of mGlu5 receptors promotes differentiation of ES cells towards the neuroectoderm lineage even under proliferating conditions (i.e. in the presence of LIF). ${ }^{16}$ Here, we have shown that ES cells maintain the expression of mGlu5 receptors when they are forced to differentiate into neurons by switching the growing medium into a specific chemically defined medium (the N2/B27 medium) lacking both serum and LIF. Under these conditions, mGlu5 receptor blockade with MPEP increased the rate of appearance of the neuronal marker, $\beta$-tubulin, and increased the number of putative GABAergic neurons immunopositive for the GAD. MPEP behaves as a negative allosteric modulator of mGlu5 receptors, thus inhibiting receptor function independently of the concentration of ambient glutamate..$^{20,21}$ This is particularly relevant to this model because ES cells release micromolar amounts of glutamate in the medium. ${ }^{16}$ As an alternative differentiation protocol, ES cells were plated onto a non-adhesive substrate in a serum-containing medium deprived of LIF. In this particular case, ES cells give rise to cells of EBs, which can be further differentiated into neurons by the addition of RA followed by re-plating in a DMEM/F12/ $\mathrm{N} 2$ medium. This protocol of differentiation is known to produce a progressive loss of mGlu5 receptors associated with the appearance of mGlu4 receptors. ${ }^{18}$ Pharmacological activation of mGlu4 receptors with the non-subtype-selective orthosteric agonist, L-AP4, has been shown to increase the expression of the early neural markers, Nestin and DIx-2 in cells of EBs driven to differentiate towards a neural lineage. ${ }^{18}$ Here, we have extended these findings showing that L-AP4 itself or the selective mGlu4 receptor enhancer, $\mathrm{PHCCC},{ }^{26}$ amplified the further steps of RA-induced differentiation into fully developed neurons. Treatment with L-AP4 or PHCCC favoured the appearance of a mature GABAergic phenotype, and rendered newly developed neurons able to respond to membrane depolarization with an enhanced release of GABA. The difference between L-AP4 and PHCCC is that the former acts as an orthosteric agonist binding to the glutamate-binding site of mGlu4 receptors, whereas the latter behaves as a receptor 'enhancer', by amplifying receptor function only in the presence of glutamate, i.e. in an activity-dependent manner. The use of these two drugs allow us to conclude that activation of mGlu4 receptors facilitates ES cell differentiation into putative GABAergic neurons in the presence of RA. In addition, the activity of L-AP4 - which shares with glutamate the binding to the same orthosteric recognition site-suggests that mGlu4 receptors are not saturated by endogenous glutamate under our culture conditions. Experiments with the cAMP analogue, 8-Br-cAMP, indicate that inhibition of cAMP formation largely contributes to the differentiating activity of mGlu4 receptors towards GABAergic neurons.

Taken together, these data gain new insights into the physiology of ES cell differentiation, and may suggest novel strategies for the optimization of cell replacement therapies.
First, either mGlu5 receptor antagonists or mGlu4 receptor agonists/enhancers might be used as adjunctive drugs in in vitro protocols of differentiation, thus facilitating ES cell commitment towards a neuronal phenotype. Alternatively, drugs like MPEP or PHCCC, which can readily cross the blood-brain barrier, ${ }^{27-29}$ might be administered to recipient animals to facilitate neuronal differentiation of ES cells implanted into the brain parenchyma. This strategy might be particularly helpful for cell replacement therapy in models of Huntington's disease that are characterized by a selective loss of GABAergic neurons in the striatum. At least MPEP might provide a dual mechanism of action by facilitating cell replacement and protecting resident neurons at the same time. Accordingly, MPEP has been shown to protect striatal medium spiny GABAergic neurons against excitotoxic damage ${ }^{30-32}$ and to prolong life span in $R 6 / 2$ transgenic mice expressing a small $\mathrm{N}$-terminal portion of human huntingtin with an expanded polyglutamine stretch. ${ }^{33}$

\section{Materials and Methods}

Materials. Methyl-6-(phenylethynyl)-pyridine (MPEP), n-phenyl-7-(hydroxyimino) cyclopropa[b]chromen-1a-carboxamide (PHCCC), L-(+)-2-amino-4-phosphonobutanoate (L-AP4), vigabatrine and SKF89976A were purchased from Tocris Cookson Ltd, UK. 8-Br-cAMP was purchased from Sigma, Milan, Italy. DMEM, DMEM/F12, Knockout-DMEM, penicillin-streptomycin, 2-mercaptoethanol, and MEM non-essential amino-acid solution were purchased from GIBCO/Life Science, Milan, Italy. Mouse monoclonal Neuronal Class III $\beta$-Tubulin (TUJ1) antibody was from Covance, Berkeley, CA. Mouse monoclonal glial fibrillary acidic protein (GFAP) antibody was from Encor Biotechnology, Alachua, FL. Mouse monoclonal antityrosine hydroxylase $(\mathrm{TH})$ clone $\mathrm{TH}-2$ and rabbit polyclonal anti-glutamate decarboxylase $65 / 67\left(\mathrm{GAD}_{65 / 67}\right)$ antibodies were from Sigma, Milan, Italy. Rabbit polyclonal anti-mGlu5 receptor antibody was from Upstate, Milan, Italy. All secondary antibodies were from GE Healthcare $\mathrm{GmbH}$ Europe, Milan, Italy. L-[G- $\left.{ }^{3} \mathrm{H}\right] \mathrm{Glutamic}$ acid was from GE Healthcare Europe $\mathrm{GmbH}$, Milan, Italy.

Cell cultures. The embryonic ES-D3 cell line derived from 129/Sv $+c /+p$ mouse was purchased from ATCC. The routine growth of these cells was performed as described previously. ${ }^{16,34}$ For the induction of neural differentiation, ES cells were cultured either as monolayer cultures exposed to DMEM/F12 supplemented with B27, a chemically defined medium known to favour the appearance of the neural phenotype (protocol 1); or, alternatively, as EBs in the presence of $1 \mu \mathrm{M} \mathrm{RA}$ (protocol 2). In protocol 1, undifferentiated ES cells were plated onto gelatin-coated dishes and cultured for 6 days in serum-free N2B27 medium containing DMEM/F12/ N2 (35\%) and neurobasal/B27 (65\%). ${ }^{19}$ The higher percentage of neurobasal/B27 $(65 \%)$ was selected to improve cell attachment and viability according to Ying and Smith. ${ }^{35}$ Thereafter, cells were trypsinized and re-plated on fibronectin-coated dishes and cultured in the same medium for additional 6 or 12 days. In protocol 2, undifferentiated ES cells were induced to differentiate into EBs by withdrawal of LIF and plating onto a non-adhesive substrate. EBs were cultured for 4 days in the absence of all-trans-RA followed by 4 days in the presence of $1 \mu \mathrm{M}$ RA $(4-/ 4+$ induction). At the end of the induction period, EBs were re-plated on gelatin-coated dishes and cultured for 6 or 12 additional days in serum-free DMEM/F12 supplemented with $\mathrm{N} 2 .^{34,36}$

Measurement of glutamate concentration in cell culture media. Medium glutamate levels were measured after pre-column derivatization with o-phthaldialdehyde (OPA) followed by HPLC with fluorescence detection. ${ }^{16}$

Western blot analysis. Western blot analysis was performed as described previously. ${ }^{16}$ Briefly, protein extracts were separated by SDS-gel electrophoresis and transferred to nitrocellulose membrane. The filter was blocked with $5 \%$ bovine serum albumin for $2 \mathrm{~h}$ with primary antibodies. Antibodies were used at the following dilutions: mouse monoclonal anti-Neuronal Class III $\beta$-Tubulin, 1:500; mouse monoclonal anti-GFAP antibody, 1:1000; mouse monoclonal anti-TH antibody, 1:1000; rabbit polyclonal anti-GAD ${ }_{65 / 67}$ antibody, 1:1000; rabbit polyclonal 
anti-mGlu5 receptor antibody, 1:1000. The membrane was then incubated with a horseradish-peroxidase-conjugated secondary antibody and developed with enhanced chemiluminescence PLUS reagent, from GE Healthcare Europe $\mathrm{GmbH}$, Milan, Italy. The levels of the housekeeping proteins we have tested ( $\beta$-actin, GAPDH) changed substantially during differentiation. Thus, densitometric values of all differentiation markers were normalized by the amount of proteins loaded in the gel by staining with Pelican Indian ink $(1 \mu / / \mathrm{ml}$ in $0.2 \%$ Tween-20 in Tris-buffered saline (TBS))

Immunocytochemistry. Cultures were fixed in $4 \%$ paraformaldehyde in phosphate-buffered saline (PBS) for $5 \mathrm{~min}$, incubated with blocking buffer (TBS, $2 \%$ normal goat serum, $+0.1 \%$ digitonin) for $30 \mathrm{~min}$ followed by incubation with rabbit polyclonal anti-GAD $65 / 67$ antibody (1:100), mouse monoclonal anti- $\beta$ III-tubulin antibody (1:100), and mouse monoclonal anti-GFAP (1:400) in blocking buffer overnight at $4^{\circ} \mathrm{C}$. After washing with PBS, adherent cells were incubated with a fluorescein isothiocyanate-labelled secondary antibody (goat anti-rabbit IgG1, 1:200), Texas red-labelled secondary antibody (goat anti-IgM, 1:500), washed three times with PBS and examined under a confocal microscope (Nikon C1 plus). Alternatively, immunostaining was revealed by the avidin-biotin-peroxidase following incubation with biotinylated secondary antibody, and $A B C$ Elite solution (Vector Laboratories, DBA, Milan, Italy).

cAMP assay. EBs at 4 DIV were incubated for $15 \mathrm{~min}$ in Krebs-Henseleit buffer in the presence of $0.5 \mathrm{mM}$ isobutylmethylxanthine. Soon after, EBs were exposed to forskolin $(10 \mu \mathrm{M})$ and PHCCC $(30 \mu \mathrm{M})$ for additional 25 min. Reaction was stopped by the addition of one volume of $0.8 \mathrm{~N} \mathrm{HClO}_{4}$. After neutralization with $2 \mathrm{M} \mathrm{K}_{2} \mathrm{CO}_{3}$, the intracellular content of CAMP of each sample was determined using a commercial radioimmunoassay kit (Amersham, Milan, Italy).

GABA release. Experiments were performed on day 6 and day 12 after plating of EBs in DMEM/F12/N2. Cells were incubated in Krebs-Henseleit with $1 \mu \mathrm{Ci}$ of ${ }^{3} \mathrm{H}$-glutamate (sp. act. $49 \mathrm{Ci} / \mathrm{mmol}$ ) for $1 \mathrm{~h}$ at $37^{\circ} \mathrm{C}$, washed three times at 2-min intervals in the same medium, and then incubated with vigabatrine $(100 \mu \mathrm{M})$ and SKF89976A $(10 \mu \mathrm{M})$ for $10 \mathrm{~min}$. Experiments were performed in the absence or presence of $\mathrm{KCl}(50 \mathrm{mM})$. The medium was collected after $10-15 \mathrm{~min}$ and the reaction was stopped with $0.1 \mathrm{~N} \mathrm{HClO}_{4}$. After centrifugation, samples were acidified with $0.01 \mathrm{~N} \mathrm{HCl}$, derivatized with 0 -phthalaldehyde and mercaptoethanol, and analysed by gradient HLPC. The HPLC apparatus consisted of a programmable solvent module 126 (Beckman Instrument, Fullerton, CA), an analytical C-18 reverse-phase column kept at $30^{\circ} \mathrm{C}$ (Ultrasfere ODS $5 \mu \mathrm{m}$ Spherical, $80 \mathrm{~A}$ pore, $2 \mathrm{~mm} \times 15 \mathrm{~cm}$, Beckman Instrument) and a RF-551 spectrofluorometric detector (Shimadzu). Excitation and emission were set at 360 and $450 \mathrm{~nm}$, respectively. The radioactivity present in the peak co-eluting with authentic GABA was collected and counted. ${ }^{37}$

1. Kinzie JM, Saugstad JA, Westbrook GL, Segerson TP. Distribution of metabotropic glutamate receptor 7 messenger RNA in the developing and adult rat brain. Neuroscience 1995; 69: 167-176.

2. Sampaio LF, Paes de Carvalho R. Developmental regulation of group III metabotropic glutamate receptors modulating adenylate cyclase activity in the avian retina. Neurochem Int 1998; 33: 367-374.

3. Di Giorgi Gerevini V, Caruso A, Cappuccio I, Ricci Vitiani L, Romeo S, Della Rocca C et al. The mGlu5 metabotropic glutamate receptor is expressed in zones of active neurogenesis of the embryonic and postnatal brain. Brain Res Dev Brain Res 2004; 150: 17-22.

4. Lujan R, Shigemoto R, Lopez Bendito G. Glutamate and GABA receptor signalling in the developing brain. Neuroscience 2005; 130: 567-580.

5. Canudas AM, Di Giorgi Gerevini V, lacovelli L, Nano G, D'Onofrio M, Arcella A et al. PHCCC, a specific enhancer of type 4 metabotropic glutamate receptors, reduces proliferation and promotes differentiationof cerebellar granule cell neuroprecursors. J Neurosci 2004; 24: 10343-10352.

6. Di Giorgi Gerevini V, Melchiorri D, Battaglia G, Ricci Vitiani L, Ciceroni C, Buscati CL et al. Endogenous activation of metabotropic glutamate receptors supports the proliferation and survival of neural progenitor cells. Cell Death Differ 2005; 12: 1124-1133.

7. Luyt K, Varadi A, Halfpenny CA, Scolding NJ, Molnar E. Metabotropic glutamate receptors are expressed in adult human glial progenitor cells. Biochem Biophys Res Commun 2004 319: $120-129$

8. Luyt K, Varadi A, Durant CF, Molnar E. Oligodendroglial metabotropic glutamate receptors are developmentally regulated and involved in the prevention of apoptosis. J Neurochem 2006; 99: 641-656.

9. Skerry T, Genever PG. Glutamate signalling in non-neuronal tissues. Trends Pharmacol Sci 2001; 22: 174-181.
10. Arcella A, Carpinelli G, Battaglia G, D'Onofrio M, Santoro F, Ngomba RT et al. Pharmacological blockade of group II metabotropic glutamate receptors reduces the growth of glioma cells in vivo. Neuro Oncol 2005; 7: 236-245.

11. lacovelli L, Arcella A, Battaglia G, Pazzaglia S, Aronica E, Spinsanti $P$ et al. Pharmacological activation of mGlu4 metabotropic glutamate receptors inhibits the growth of medulloblastomas. J Neurosci 2006; 26: 8388-8397.

12. Pollock PM, Cohen Solal K, Sood R, Namkoong J, Martino JJ, Koganti A et al. Melanoma mouse model implicates metabotropic glutamate signaling in melanocytic neoplasia. Nat Genet 2003; 34: 108-112

13. Chang HJ, Yoo BC, Lim SB, Jeong SY, Kim WH, Park JG et al. Metabotropic glutamate receptor 4 expression in colorectal carcinoma and its prognostic significance. Clin Cancer Res 2005; 11: 3288-3295.

14. Ango F, Prezeau L, Muller T, Tu JC, Xiao B, Worley PF et al. Agonist-independent activation of metabotropic glutamate receptors by the intracellular protein Homer. Nature 2001; 411: 962-965.

15. De Blasi A, Conn PJ, Pin J, Nicoletti F. Molecular determinants of metabotropic glutamate receptor signaling. Trends Pharmacol Sci 2001; 22: 114-120.

16. Cappuccio I, Spinsanti P, Porcellini A, Desiderati F, De Vita T, Storto M et al. Endogenous activation of mGlu5 metabotropic glutamate receptors supports self-renewal of cultured mouse embryonic stem cells. Neuropharmacology 2005; 49 (Suppl 1): 196-205.

17. Spinsanti P, De Vita T, Di Castro S, Storto M, Formisano P, Nicoletti F et al. Endogenously activated mGlu5 receptors sustains the increase in c-Myc expression induced by leukaemia inhibitory factor in cultured mouse embryonic stem cells. J Neurochem 2006; 99 : 299-307.

18. Cappuccio I, Verani R, Spinsanti P, Niccolini C, Gradini R, Costantino S et al. Contextdependent regulation of embryonic stem cell differentiation by mGlu4 metabotropic glutamate receptors. Neuropharmacology 2006; 51: 606-611.

19. Ying QL, Stavridis M, Griffiths D, Li M, Smith A. Conversion of embryonic stem cells into neuroectodermal precursors in adherent monoculture. Nat Biotechnol 2003; 21 183-186.

20. Varney MA, Lin FF, Jachec C, Rao SP, Hess SD, Johnson EC et al. Stable expression of human NMDA receptors in cultured mammalian cells. Methods Mol Biol 1999; 128 43-59.

21. Pagano A, Ruegg D, Litschig S, Stoehr N, Stierlin C, Heinrich M et al. The non-competitive antagonists 2-methyl-6-(phenylethynyl)pyridine and 7-hydroxyiminocyclopropan $[b]$ chromen-1a-carboxylic acid ethyl ester interact with overlapping binding pockets in the transmembrane region of group I metabotropic glutamate receptor. J Biol Chem 2000; 275 33750-33758.

22. Guan K, Chang H, Rolletschek A, Wobus AM. Embryonic stem cell-derived neurogenesis. Retinoic acid induction and linear selection of neuronal cells. Cell Tissue Res 2001; 305 171-176.

23. Bibel M, Richter J, Schrenk K, Tucker KL, Staiger V, Korte M et al. Differentiation of mouse embryonic stem cells into a defined neuronal lineage. Nat Neurosci 2004; 7 1003-1009.

24. Tanabe Y, Nomura A, Masu M, Shigemoto R, Mizuno N, Nakanishi S. Signal transduction, pharmacological properties, and expression patterns of two rat metabotropic glutamate receptors, mGluR3 and mGluR4. J Neurosci 1993; 13: 1372-1378.

25. Bjorklund $A$, Lindvall $O$. Cell replacement therapies for central nervous system disorders. Nature Neurosci 2000; 3: 537-544.

26. Maj M, Bruno V, Dragic Z, Yamamoto R, Battaglia G, Inderbitzin W et al. PHCCC, a positive allosteric modulator of mGluR4: characterization, mechanism of action, and neuroprotection. Neuropharmacology 2003; 45: 895-906.

27. Yu M, Tueckmantel W, Wang X, Zhu A, Kozikowski AP, Brownell AL. Methoxyphenylethynyl, methoxypyridylethynyl and phenylethynyl derivatives of pyridine: synthesis, radiolabeling and evaluation of new PET ligands for metabotropic glutamate subtype 5 receptors. Nucl Med Biol 2005; 32: 631-640.

28. Storto M, Capobianco L, Battaglia G, Molinaro G, Gradini R, Riozzi B et al. Insulin secretion is controlled by mGlu5 metabotropic glutamate receptors. Mol Pharmacol 2006 69: $1234-1241$

29. Battaglia G, Busceti CL, Molinaro G, Biagioni F, Traficante A, Nicoletti $F$ et al. Pharmacological activation of mGlu4 metabotropic glutamate receptors reduces nigrostriatal degeneration in mice treated with 1-methyl-4-phenyl-1,2,3,6-tetrahydropyridine. J Neurosci 2006; 26: 7222-7229.

30. Bruno V, Ksiazek I, Battaglia G, Lukic S, Leonhardt T, Sauer D et al. Selective blockade of metabotropic glutamate receptor subtype 5 is neuroprotective. Neuropharmacology 2000; 39: 2223-2230.

31. Battaglia G, Fornai F, Busceti CL, Aloisi G, Cerrito F, De Blasi A et al. Selective blockade of mGlu5 metabotropic glutamate receptors is protective against methamphetamine neurotoxicity. J Neurosci 2002; 22: 2135-2141.

32. Popoli P, Pintor A, Tebano MT, Frank C, Pepponi R, Nazzicone V et al. Neuroprotective effects of the mGluR5 antagonist MPEP towards quinolinic acid-induced striatal toxicity: involvement of pre- and post-synaptic mechanisms and lack of direct NMDA blocking activity. J Neurochem 2004; 89: 1479-1489.

33. Schiefer J, Sprunken A, Puls C, Luesse HG, Milkereit A, Milkereit E et al. The metabotropic glutamate receptor 5 antagonist MPEP and the mGluR2 agonist LY379268 modify disease progression in a transgenic mouse model of Huntington's disease. Brain Res 2004; 1019: 246-254. 
34. Bain G, Ray WJ, Yao M, Gottlieb DI. Retinoic acid promotes neural and represses mesodermal gene expression in mouse embryonic stem cells in culture. Biochem Biophys Res Commun 1996; 223: 691-694.

35. Ying QL, Smith AG. Defined conditions for neural commitment and differentiation. In Wassarman PM, Keller GM (eds). New York: Academic Press Methods in Enzymology. 2003; 365, pp 327-345.
36. Okada Y, Shimazaki T, Sobue G, Okano H. Retinoic acid concentration-dependent acquisition of neural cell identity during in vitro differentiation of mouse embryonic stem cells. Dev Biol 2004; 275: 124-142.

37. D'Onofrio M, Arcella A, Bruno V, Ngomba T, Battaglia G, Lombari V et al. Pharmacological blockade of mGlu2/3 metabotropic glutamate receptors reduces cell proliferation in cultured human glioma cells. J Neurochem 2003; 84: 1288-1295.

Supplementary Information accompanies the paper on Cell Death and Differentiation website (http://www.nature.com/cdd) 